\title{
Strategic change in the academy: controlling and/or enabling strategies
}

\author{
John Pisapia ${ }^{a}$, Tony Townsend ${ }^{b, c, d}$ and Jamila Razzaq ${ }^{d_{*}}$ \\ ${ }^{a}$ Educational Leadership, Florida Atlantic University, Boca Raton, FL, USA; ${ }^{\mathrm{b}} \mathrm{School}$ of Education, University of \\ Tasmania, Tasmania, Australia; 'Griffith Institute for Educational Research, Griffith University, Nathan, \\ Australia; dSchool of Education, University of Glasgow, Glasgow, UK
}

\begin{abstract}
This study describes the strategic change efforts of a university in the United Kingdom which changed its form and resource deployments to focus on the production of interdisciplinary research. A problem-oriented case study method was used to chronicle and analyse the leadership strategies and tactics employed and their consequences. We found that the reliance on a vertical leadership (controlling) strategy led to external legitimization but not internal legitimacy. We also found instances these strategies created unintended consequences which inhibited the strategic change initiative. In particular, horizontal leadership (enabling) strategies that spoke to the academic heartland were muted. We concluded that in universities undertaking major strategic change efforts controlling influence actions may be necessary but they are insufficient to levers of strategic change. The study is particularly important because it contributes to an understanding of strategic change in universities at a time when most such efforts fail to meet their objectives and there is a limited empirical literature to draw upon.
\end{abstract}

\section{KEYWORDS}

Strategic change; vertical and horizontal leadership; controlling and enabling strategies; social networks; university leadership

... there is no more delicate matter to take in hand, nor more dangerous to conduct, nor more doubtful in its success, than to set up as a leader in the introduction of changes. For he who innovates will have for his enemies all those who are well off under the existing order of things, and only lukewarm supporters in those who might be better off under the new. (Machiavelli, 1992, p. 13)

\section{Introduction}

The pressure for strategic change in the academy is not new. In the past, strategic decisions have been made to accommodate new technologies, democratization of knowledge, globalisation, programme design and delivery, tuition, and student access. What is new are challenges that go to the core of the academy in terms of its role, relevancy, and modes of operation attributed to its seemingly inability to address intractable societal 
problems such as climate change, health care, and political disruptions. These new change forces led funders of academic research to increasingly call upon universities to produce collaborative, interdisciplinary research focused on larger societal needs (National Academy of Sciences, 2004; Rhoten, 2003). They require strategic change if they are to be met. This case study documents how one university in the United Kingdom attempted to meet this strategic challenge.

Strategic change refers to a departure from established structures and routines towards untested novel ones by realigning with an organization's external environment in order to gain competitive advantages (Pisapia, 2009; Rajagophalan \& Sprieitzer, 1996). Strategic changes are context dependent, unpredictable, and non-linear and usually complex, consequential, and many times controversial (Pisapia, 2009). In such an environment strategic change initiatives may lead to unanticipated consequences which occur because

- it is impossible to anticipate everything,

- of errors in analysis of the problem,

- of following habits that worked in the past but may not apply to the current situation,

- immediate interests overriding long-term interests, and

- fear that basic values (culture) might change.

What results is managerial actions designed to both control and enable the change (Balogun \& Johnson, 2005; Harris \& Ogbonna, 2002; Merton, 1936).

As Machiavelli warned, change of this magnitude is a delicate matter and leader actions to support it cannot be ill advised. We turned to the celebrated higher education scholar Burton Clark's study of five European universities in the mid-1990s for guidance. Clark's (1998a, p. 5) conclusion was that there were five common intentional acts leaders used in to guide strategic change and create entrepreneurial universities. They strengthened the managerial core, enhanced developmental periphery, developed a diversified funding base, stimulated the academic heartland, and developed an entrepreneurial culture to transform universities. This case study of strategic change in a university in the United Kingdom is informed by Clark's elements.

The paper reports on a study conducted in 2012 in one university in the United Kingdom. One broad question and four specific questions were posed to guide the research: How was the interdisciplinary change initiative organized, led, and supported at the university, college, school, and department levels? Did leader, manager, or professorial mindsets interfere or facilitate the interdisciplinary change initiative? What specific leader actions facilitated or impeded the interdisciplinary change initiative? Were there any unintended consequences of these efforts? Overall, how would the success of these efforts be rated? The first question served to identify key organizational and leader actions that influenced the change process. The remaining questions were used to identify and assess the effect of cognition and leader actions on the strategic change initiative. It considers the current context in which UK universities are operating and provides findings that might assist them in navigating the somewhat murky waters ahead when it comes to focusing attention and resources on interdisciplinary research. 


\section{Study aims and contributions}

This case study examines the consequences (anticipated and unanticipated) of managerial actions in a strategic change effort in a university which when faced with dwindling productivity and external pressure changed its form and resource deployments to focus its research efforts on the production of interdisciplinary research. The study illuminates the strategies, choices, and tactics employed by the university's leadership team and its agents at other university levels, as well as the consequences of those decisions.

The study's main contributions are that its findings add to a limited knowledge of strategic change in universities (By, 2005) and should be of value to those who lead such institutions. Roughly $70 \%$ of change initiatives in organizations fail, regardless of industry (Keller \& Price, 2011). Though controversial (Hughes, 2011), this staggering statistic is even more critical for university systems faced with decreasing relevance regarding solving intractable societal problems, technology expansions, and increased student consumerism, dwindling educational standards and budgets. Further, our study suggests a number of practical controlling and enabling strategies for university leaders contemplating strategic changes of their universities. In doing this, the study extends limited research findings regarding strategic change $(B y, 2005)$ particularly in universities (Meyer, Gaba, \& Colwell, 2005). For example, Li, Guohui, and Eppler's (2008) meta-analysis of strategy implementation studies identified nine recurring factors influencing strategy implementation, none of which targeted leadership influence actions specifically (p. 11).

\section{Theoretical considerations}

The process view of strategic change views it as an iterative process where managers probe the environment through small learning steps which can shape resistance or create the need for change (Rajagophalan \& Sprieitzer, 1996). In the process view, strategic change is viewed as continuous and evolutionary or, as in the case of this paper, discontinuous and revolutionary.

The studies cited in the preceding paragraphs suggest that from a strategic perspective, the dynamics of any change initiative will be influenced by the organization or industry's culture and traditions. As James Duderstadt, President Emeritus of the University of Michigan, observed in 2000, it is difficult for leaders in universities to influence the work of all critical constituencies at the same time. State and federal government intrusions in university affairs, public expectations for efficient management, student interest in the cost of their education and employability all need to be balanced, while staff involvement in academic matters continues to take the form of debate and consensus which slows adaptation. Higher education institutions have traditionally been cushioned from such environmental pressures for change because of their more consensual manner of governing and the chasm between academic staff and administrators.

Strategic change not only encompasses the selection of a purposeful direction (in the case of this study - interdisciplinary research), but also leader influence actions used to realign organizational structures, resources, and processes to ensure the desired outcome. Rajagophalan and Sprieitzer (1996, p. 73) highlighted three managerial actions that influence performance during strategic changes: (1) actions that mitigate resistance to change, (2) actions that build environmental support which enhance the 
range of options and resources, and (3) learning from their change experience and modifying previous actions. When strategic change involves a shift in underlying organizational ideologies it is viewed as transformational (Rajagophalan \& Sprieitzer, 1996). Thus, in the unique culture of universities the choice of leader influence actions may lead to success or failure (Birnbaum, 2000; Duderstadt \& Womack, 2003; Tierney, 1988).

Merton's (1936) notion of unintended consequences of leader actions suggests that purposeful leader actions do not always result in change. When purposeful leader actions meet internal routines, interests, and values unintended consequences may result which can stifle change efforts. This does not have to be the case. For instance, staff support for strategic change initiatives is bolstered when they feel they are part of it (Welsh \& Metcalf, 2003); when shared meanings develop (Gioia \& Thomas, 1996); when top managers communicate face to face (Jarzabkowski, 2008); when the definition of quality is based on outcomes not resource inputs; and when it supports their discipline and their educative mission (Welsh \& Metcalf, 2003).

We chose vertical and horizontal leadership lenses to understand why change happened or did not in this case. Traditionally strategic change has been viewed in topdown vertical terms (Balogun \& Johnson, 2005; Pearce, 2004) even though there is strong support to view it as an emergent process (French, 2009; Gouldner, 1954; Harris \& Ogbonna, 2002; Pettigrew, 1985). This interplay of change from above and emerging behaviour from below is poorly understood (Birkinshaw, Crilly, Bouquet, \& Lee, 2016).

Vertical theory frames leadership tasks as the relationship between leaders, followers, and common goals (Bass, 1990; Blake \& Mouton, 1964; Burns, 1978; Fiedler, 1967; Fu \& Yukl, 2000; House, 1971; Triandis, 1995). Vertical leadership is commonly expressed in hierarchal relationships with power residing with the formal leader who directs and limits participation with the intent of providing tighter accountability and efficiency. In vertical relationships controlling strategies such as command, control, and persuasion tactics are the levers of change. A frequent tactic is to change organizational structures and systems (Rajagophalan \& Sprieitzer, 1996). There is little, if any, focus on organizational context (Boal \& Hooijberg, 2000; House \& Aditya, 1997). It is thought that by using these controlling levers organizations will succeed (Meyer \& Rowan, 1977, p. 342). Yet, the evidence suggests that these levers, which have served well in the past, may not work well in universities which are rife with competing interests, and differing perspectives, objectives, and fuzzy goals (Birnbaum, 1991; Cyert \& March, 1963; Kezar, 2001; Pfeffer, 1981). Furthermore, ignoring such contextual realities frequently inhibits strategic alignment with external forces (Baer, Dirks, \& Nickerson, 2013).

Horizontal theory frames leadership tasks as the relationship among individuals working in collective effort independent of hierarchical roles (Day, 2000). It builds on distributed leadership theory (Cox, Pearce, \& Perry, 2003; Gronn, 2002; Pearce \& Conger, 2003). However, its core thoughts emanate from complexity science (Goldstein, Hazy, \& Lichtenstein, 2010; Lichtenstein et al., 2006; Uhl-Bien, Marion, \& McKelvey, 2007), and relational theories (Drath, 2001; McNamee and Gergen, 1999; Uhl- Bien, 2006). At its core are the notions that everything is connected to everything else (Barabási, 2002), and that social relationships may influence the direction, speed, and depth of change efforts (McGrath \& Krackhardt, 2003; Tenkasi \& Chesmore, 2003). In horizontal relationships, enabling strategies such as communication, co-creation, coordination, minimum specifications, shared meanings, network, and trust building tactics are the levers of change (Drath, 
2001; Goldstein et al., 2010; Lichtenstein et al., 2006; Pisapia, 2009; Uhl-Bien et al., 2007). These enabling strategies, used to focus on the process rather than the content of the work, are thought to hold the promise for greater effectiveness in times of ambiguity and uncertainty.

In seeking to establish how the change initiative of moving towards an interdisciplinary research structure, both in terms of academic activity and university restructuring, was handled, the current study sought to establish if, and how, both vertical and horizontal theories of change were in play, and, if so, what the impact of both was on change and staff response to change.

\section{Methods}

\section{Research setting}

The focal point for this case study is a strategic change that took place at an urban broadbased, research-intensive institution with global reach in the United Kingdom over the course of six months. In 2012, this university (hereafter identified as the Great Western University (GWU)) ranked in the top $1 \%$ of the world's universities. It welcomed students from 120 countries worldwide who rated the university near the top in the United Kingdom for international student satisfaction. There were more than 23,000 undergraduate and postgraduate students who were served by approximately 6,000 staff.

The unit of analysis of the current case study was selected to gain insight into the nature of strategic change in higher education institutions. This university was purposefully selected because it had recently initiated a complete strategic restructuring of its purposes, procedures, and structure (from faculties and departments to colleges and schools) to support interdisciplinary research which enabled us to view and learn from the intended and unintended consequences of vertical and horizontal leader actions. Dualities, such as the fact that interdisciplinary research must compete with other social and organizational responsibilities including disciplinary research and traditions, stress university leaders. As Clark (1998b, p. 8) noted, the central university management challenge is finding a way to move from a passive to active mode when historically the customary mandate of its internal faculties and departments traditionally focused on oversight of their particular fields and protection of their own material interests. Since the underlying traditional academic culture cannot be ignored, nor pushed aside, it must be put to work and thereby adapted. Hence, we take our cues from scholars working from the process school of strategic change (Rajagophalan \& Sprieitzer, 1996) and focus on the roles, influence actions, and tactics of university leaders to create alignment and further the strategic change effort.

\section{Research design}

The focus of this research is on the experiences of those charged with implementing the strategic change initiative at GWU. Thus, the present study uses a phenomenological interpretive philosophy where the meaning of events and phenomenon are explored from the subject's perspective (Morrison, 2007, p. 26). From Layder's (2006) view on phenomenology meaning arises from the world of daily experiences as it is lived ( $p .93)$. The study 
endeavours to capture different aspects of the participants' experience and responses through evaluative, critical, and speculative comments. Under the phenomenological umbrella, a problem-oriented case study of strategic change was employed. The rationale of choosing this method was based on criteria recommended by Yin (2009) (i.e. need to answer how and why questions, little research control over variables, and a focus on real-life context), and its explanatory power (Van de Ven, 1992; Yin, 2009).

\section{Data collection and analysis}

At the level of methods, this study used triangulation by mixing types and sources of data. As suggested by Podsakoff, MacKenzie, Podsakoff, and Lee (2003), we included four data sources: (a) academic staff, (b) work unit managers, (c) university managers, and (d) organizational archival data. Thus, the study design was a good fit for our purposes as an effort was made to have the experiences of top-level university managers, middle-level managers, and academic faculty as the core contributors to the research. Triangulation was also pursued by drawing from three sources of information: (a) open-ended questions on a survey, (b) interviews, and (c) document review of university records related to the change initiative. All respondents were promised confidentiality. The data stemming from these data types and sources provides a rich tapestry from which to identify emerging themes and create meaning.

This inquiry was conducted by a team of three researchers. Three months were spent carrying out focus groups, semi-structured informal interviews, constructing and gathering responses to an open ended survey, and locating and analysing archival documents. Data analysis was carried out over the following three months.

The data collection process followed several steps. Archival data, collected from university websites, publications, and official university documents such as descriptions of institutes, centres, networks and clusters, as well as official university strategic plans and implementing documents and presentations to the governing board, were the first source of data utilized. These data provided both useful background material necessary for understanding the university's position, but also were helpful in constructing the staff survey. Interdisciplinary research has been defined in a particular way, as

teams or individuals that integrates information, data, techniques, tools, perspectives, concepts, and/or theories from two or more disciplines or bodies of specialized knowledge to advance fundamental understanding or to solve problems whose solutions are beyond the scope of a single discipline or area of research practice. (National Academy of Sciences, 2004, p. 2)

This is somewhat different from multidisciplinary research - different disciplinary perspectives on the same issue and transdisciplinary research - where a completely new discipline is created (Razzaq, Townsend \& Pisapia, 2013, p. 154). We pointed out that in a single university document there were 14 different versions of the words "multidisciplinary," "interdisciplinary," and "cross-disciplinary" used, with different spelling or hyphenation, all of which seemed to be describing just 1 form of research (Razzaq, Townsend \& Pisapia, 2013, p. 160). This suggested a level of uncertainty by university administrators in understanding the terminology that they were promoting, and this led to the development of 
questions to establish whether staff were equally uncertain about what "interdisciplinary" research was.

Then, college-level focus groups were conducted with participants identified by college administrators as supportive or having concerns with the strategic change initiative, or had roles in the initiative conceptualization. These were open-ended discussions to give researchers insights as to the change process and assure that questions asked in the interviews and survey would provide appropriate data. Comments were recorded.

In keeping with the interpretive philosophy of the study, 25 semi-structured 1-hour interviews on the central study questions were held with targeted participants from across the university. The semi-structured nature of the interview was designed to provide prompts that enable interviewees to tell "what is in (or on) their minds and avoid those that put things there" (Cohen, Manion, \& Morrison, 2007, p. 354). The interviewees were selected using a combination of judgement, snowball, and quota techniques (Remenyi, Williams, Money, \& Swartz, 1998). The participants included university administrators (4), Heads of Colleges (3), Heads of Schools (5), research coordinators (4), research team leaders (6), and team members (6). The targeted interviews were supported by archival document review and responses to open-ended surveys structured around the interview questions to gain the widest view of the implementation of the strategic change initiative.

Open-ended surveys were sent to 900 research active academic staff members in 3 of the university's 4 colleges. One hundred and twenty-seven surveys were returned for analysis. The typical respondent was male, between 40 and 60 years of age, a professor or a lecturer, housed either in the colleges of science/engineering or social science. The level of engagement of respondents in interdisciplinary research was substantial. Most respondents (64.8\%) were interested in interdisciplinary research; $84.2 \%$ were actively involved in interdisciplinary research; and $73.2 \%$ had published in interdisciplinary journals. All main academic staff ranks were represented. No university administrators responded to the survey.

Data analysis for this study was guided by the research questions and our theoretical framework, and Yin's (2009, p. 126) advice that data analysis "consists of examining, categorizing, tabulating, testing, or otherwise recombining evidence, to draw empirically based conclusions." Data analysis began as the data were collected to get a sense of the data. In addition to the archival material which helped to frame the way in which we looked at the data, the data collected included both quantitative and qualitative responses to the survey questions and transcripts of focus group meetings and interviews conducted by the research team.

An evidence sheet was created for each of the five questions posed. Data that seemed to be related to the research question were coded into the corresponding evidence sheet. At this stage the team agreed to code data into more than more than one evidence sheet to retain a true representation of the data as it emerged. Each evidence sheet was analysed for themes by individual team members and team discussions were held to identify first concepts and then themes within the data. The evidence sheet was restructured around the themes. When the evidence sheets were finalized, the research team looked for patterns across the evidence sheets as well as contrasts and paradoxes within the data (Coffey, Holbrook, \& Atkinson, 1996). Pattern matching was followed by a process of constant comparison to identify findings related to each research question. Reportable 
findings were identified when the evidence from survey, interviews, and narratives extended beyond any one academic staff member and two of the three researchers agreed. An audit trail was maintained. We took care to minimize respondent bias by triangulating different points of view on important issues using archival data where possible to verify what respondents said. Verbatim quotes are provided in following paragraphs to explain, illustrate the balance of feeling or respondents, and deepen understanding of our narrative (Corden \& Sainsbury, 2006).

\section{Results}

Our data, presented through the vertical (controlling) and horizontal (enabling) leadership lenses, as well as our findings, are descriptive (i.e. this is what did happen). The narrative and interview data are reported by the roles the respondent filled the university and this is displayed by the initials following their comments. We intentionally used quotes from numerous participants so that no one voice dominated. This approach also helped us to note if there was a collective voice. For information taken from archival data, the document is cited. The results that follow are sequenced thusly: the statement of the overarching theme, and the emergent categories in every theme followed by a summary of issues within each category.

\section{Vertical leadership}

\section{How was the interdisciplinary change initiative organized, led, and supported at the university, college, school, and department levels?}

The strategic change literature promotes three general strategies to fit organizations to their environmental change forces: organizational restructuring, portfolio restructuring, and financial restructuring. Bowman and Singh (1993) and McKinley and Scherer (2000) report that research on realignment is mixed but suggest that organizational restructuring produces weaker effects than financial or portfolio restructuring. Yet, they noted that most realignment efforts follow the organizational strategy.

University leaders at GWU chose the organization realignment strategy and applied vertical leader actions to implement the changes necessitated to restructure the university to produce interdisciplinary research. Realignment efforts were focused on the university's big structures - operating units - control systems through a forcing strategy. Routines and work processes were only dealt with in a reactive mode as in the case of allowing one college to retain its departmental structure.

The strategy for launching GWU's vision was simple: eliminate faculties and departments and realign its academic resources into colleges, schools, institutes, centres, networks, and clusters. The university collapsed more than 50 individual departments from 9 faculties into 4 colleges containing 19 schools, and established 6 research institutes that would cut across colleges to enable a university-wide focus on critical areas necessitating interdisciplinary research.

Research institutes are autonomous units within GWU's colleges with dedicated university funding and are not subordinate to schools. Each college was to have one institute and new ones were to be identified for investment purposes. Institutes, however, could cross 
college boundaries and were responsible for thematic, multidisciplinary research addressing strategic research questions demanding multidisciplinary collaboration as well as delivering postgraduate training. Academic staff participation was by invitation.

Centres were charged with creating an identity and a "shared environment for specialist, thematic, normally multi-disciplinary research, bringing together academic staff and postgraduate students working on common interests." Centres were to be formally constituted bodies, generally externally funded, and judged by their reputation for leadership in the field, a competitive portfolio of research, growing their income from external sources, and their output of employable doctoral and postdoctoral students. Existing centres were evaluated and several were closed. Academic staff participation was by invitation.

Networks were constituted to foster interdisciplinary research and multidisciplinary activities; they predated the 2010 restructuring. Networks are university-level affiliationoriented structures. Conveners have no line authority over members. Networks that work well have a clear role and provide immediate benefits to the staff members as well as to a constituency and produce immediate tangible benefits. Networks operate across the university and have a budget line of $£ 7,000$ to be used for "scoping" activities and developing external partners. The funds cannot be used for paid or appropriated staff. Essentially, they form around common interests and the work comes off "the academic staff's backs," four visible, voluntary but encouraged research networks formed at GWU.

A cluster arrangement in the schools and colleges was introduced to replace departments, which were seen as the primary inhibitor of interdisciplinary research. Unlike the institutes, centres, and networks, the introduction of the clusters added a destabilizing aspect to the realignment of the university. Clusters were charged with identifying interdisciplinary research themes and organizing both research and teaching duties around them. All staff members were required to join a cluster or they were assigned. Thus, clusters unintentionally were perceived as another managerial level - "pseudo departments" as one staff member described them.

In addition to structural changes, resource realignments were pursued. A standard support staffing pattern was established for each college and school which cascaded to the clusters. For example, each college was provided with a research coordinator as were each of the schools in the college. Along with the elimination of a few long-standing centres, these resourcing changes resulted in loss of support for some and a loss of identity for many staff members. Funds gravitated to institutes and networks.

\section{Did leader, manager, or professorial mindsets interfere or facilitate the interdisciplinary change initiative?}

GWU's strategic initiative was far reaching. It affected most of the university staff, and faculties, departments, and colleges. The stated impetus for such a dramatic realignment was that GWU was producing "relatively poor international and postgraduate student numbers and research which was not consistently published in journals with high impact factors." Yet, notions of interdisciplinary research had found their way into GWU's strategic goals as early as 2006. Still, it was not until 2010, when led by a new Principal, ${ }^{1}$ that proposals for organizational realignment to support interdisciplinary research surfaced. The rationale offered for this change was to "enhance our position as one of the world's great, broad 
based, research-intensive universities." However, the focus of this proposal was clearly the needs of research funders. Official documents claimed that, "We'll create world leading, multi-disciplinary research institutes that meet our funders' strategic needs." Using this statement of intent, GWU moved quickly to support the production of interdisciplinary research by strengthening its managerial core, enhancing its developmental periphery, attempting to develop an entrepreneurial culture to transform the university and predictably ran into dissent.

At the strategic level, the controlling levers produced a consensus recognizing the importance of interdisciplinary research. The dominant logic which developed at this level led to reduction in uncertainty in the top management team (hereafter - TMT) and a strategic fit between their restructuring goals and the university's charter documents guiding the authoritative and resource dispersal. The congruence led to legitimacy in the eyes of external funders and governmental policy-makers, as well as hopes of securing resources by the TMT and those who reported to them.

\section{Were there any unintended consequences of these efforts?}

The congruence strategy to achieve clarity had unintended consequences. At the operational level, there was less congruence. For example, the university's attempt to clarify that the target audience was to be funders, students, and internationalization, left scars on academic staff. The way the TMT addressed Clark's fifth component "stimulating the academic heartland" created unintended consequences. Many among the academic staff were turned off by the phraseology suggesting change was aligned to funders' needs. The emotional and psychological makeup of many academic staff members does not respond to these types of attempts at motivating action. Motivation is an internal state that directs individuals towards certain goals and objectives (Bandura, 1986). Managers cannot directly influence this internal state, they can only create expectations on the part of the employees that their motives will be satisfied by doing the organization's work and then providing the rewards that satisfy the employee's needs (Mullins, 2006). The academic staff respondents in this study clearly said that trying to motivate them towards interdisciplinary research because funders will fund it is the wrong message for them, even if it is the right message for the university.

This disruption of previously held academic norms led to a push back against the TMT which as seen in the respondents' words found in Table 1 centred on four themes: legitimacy, university culture, unintended consequences, and unaddressed obstacles.

\section{What specific leader actions facilitated or impeded the interdisciplinary change initiative?}

Many academic staff members questioned the legitimacy of the TMT's claim that the restructuring would enhance interdisciplinary research. Legitimacy themes expanded to question TMT motives. For instance, "It's about money, not impacting knowledge; it's a means to securing funding" (AS9). Others tied the restructuring as an attack on the previously held departmental structure and research that emerged from that structure.

Second, change strategies violated the organizational culture which led to the TMT's legitimacy and motives to be questioned. At GWU, the vertical strategy supported 
Table 1. Academic push back to TMT congruence strategy.

Theme
Legitimacy
"They said restructuring would enhance interdisciplinary research - it doesn't" (AS22); "[it has
had] ... little real impact" (AS13); "Will this be the winner that it seems to be assumed it will
be?" (AS21); "[it] sounds like a Holy Grail or another bandwagon" (AS2); "It's about money, not
impacting knowledge; it's a means to securing funding" (AS9)
It's "destroying the subject integrity and disciplinary strength that is an essential prerequisite for
genuine cross-discipline collaborative research. Threatening traditional disciplines does not
promote interdisciplinarity; it only induces panic and short-term grant-chasing" (AS2); "You
can't have interdisciplinarity without having disciplinarity" (AS 11); "You don't get good
positive creative cultures where you have top down managerialism" (AS9); They argued that
"the best way to get the best research out of your researchers is to give them freedom to
pursue whatever they think is most interesting and fruitful" (AS12); "Teams cannot be pushed
together in an academic environment, it usually only works if it forms naturally, so I don't think
that having centralised strategic agendas for interdisciplinary research makes much sense,
unless incentives can be provided" (AS15)
"The management structure is onerous" (SRC1); "Great Western University is a heavily managed
institution" (SH4); "Forced collaboration on interdisciplinary 'research themes' identified
externally are a turn-off for most members of staff, they should emerge from below, not be
imposed from above" (TL5); "... Forcing it when there is no demand is just as bad" (AS12);
"Strategy and what actually happens are two different things" (AS15); "One school crafted their
themes by studying what funders were funding. In my school, I wrote them to coincide with
the mission of our old departments" (SCR1); "You can put all the management structures in
place that you want but people - especially professors - will seek and mostly find ways around
them unless they are committed to the vision" (SRC2)
Increased workloads; performance appraisal systems; competing frames of reference

Notes: Academic staff who did not identify themselves through the demographic information requested in the survey are coded as AS. Those that did identify their role on the survey or participated in the interviews were coded as $\mathrm{CH}$ : College Head; SH: School Head; CRC: college research coordinator; RC: school research coordinator; TL: interdisciplinary research team leader; TM: interdisciplinary research team member.

through administrative oversight reinforced perceptions of managerialism. Respondents argued that "Forced collaboration on interdisciplinary 'research themes' identified externally are a turn-off for most members of staff, they should emerge from below, not be imposed from above" (TL5). A college research coordinator used this analogy to crystallize the debate from the academic staff perspective. "It's like the jazz band - we can agree on the direction but don't tell me how to blow the notes or where to put my fingers."

Third, as the TMT used structural and resource forms of control, parts of the informal organization worked to get around those controls and undermine the status quo. As one academic staff member said, "Strategy and what actually happens are two different things" (AS15). For instance, at the college level an escape attempt was made by one college to retain its department structure rather than realign into clusters. Their proposal resonated with the TMT and it was accepted, leaving three colleges in a cluster alignment and one in departments. This escape was made because the college head was receptive to the request from staff. In other colleges, they were not.

Escape behaviour from the spirit of the realignment was also attempted within the schools. For example, the clusters were required to identify interdisciplinary research themes that staff could join. A school research coordinator described an escape behaviour this way: "One school crafted their themes by studying what funders were funding. In my school, I wrote them to coincide with the mission of our old departments" (SCR1). A second school research coordinator counterbalanced the effect of heavy management this way: "You can put all the management structures in place that you want but people - especially 
professors - will seek and mostly find ways around them unless they are committed to the vision" (SRC2).

Fourth, in any vertical strategic change process leaders must anticipate obstacles which need to be altered to support the change initiative. Some are normative and emotional such as those described in previous paragraphs. Others result from trying to graft the change on existing structures and processes.

\section{Overall, how would the success of these efforts be rated?}

At GWU there were obstacles to the strategic restructuring effort that went unaddressed which added to the discomfort of academic staff members. For example, the survey data we collected suggest that most staff agreed with the concept of interdisciplinary research. Eighty-four per cent of our respondents reported that they were actively involved in interdisciplinary research, and 78\% believed that interdisciplinary research was just as important as single disciplinary research and $78 \%$ believed that they had benefitted from being involved. Yet even with this level of support for the concept, there was a high level of concern about the way in which quality research is determined and funds are authorized in United Kingdom universities, especially for young staff. The perception of those who responded to the survey, attended focus groups, and were interviewed was that when they presented interdisciplinary articles for performance review in their departments, these were seen as less important than disciplinary research. Thus, they felt even though they liked participating in interdisciplinary projects, only $34 \%$ felt that this involvement improved their chances of promotion and $32 \%$ felt that the rewards available matched the effort required. If one is required to be a disciplinary expert for promotion purposes, then interdisciplinary research will only be pursued by those who have already been promoted and have already achieved the required publications. In such circumstances people were forced to choose between the new vision and their own self-interest (Kotter, 1995, p. 64).

A second unaddressed obstacle was the perceived increase in people's workloads, without any incentives to do so, or consideration of ways to lessen workloads in other ways. For instance, in moving to clusters, administrative assistance was withdrawn resulting in increased workloads. Most large change efforts require the willingness of the staff to engage and own it. However, norms of reciprocity are usually in effect. From the academic staff's perspective, if they are interested and committed they will engage willingly. If not, incentives must be applied rather than withdrawn, such as in the case of removal of administrative support staff when departments changed to clusters. If new priorities are to be addressed, workloads, old routines, and processes need to be thought through, addressed, and incentivized.

However, the data also suggest that while the dominant lever for university change was a form of vertical leadership, horizontal leadership was also evident at university, college, and individual academic staff member levels. The data suggest that if any of the activities related to the change were successful, that these methods seemed to find ways to support interdisciplinary research in a way that was acceptable. We turn now to our review of the data and to some vignettes of horizontal leadership in the university, where the research questions elicited somewhat different responses to those above. 


\section{Horizontal leadership}

While the TMT worked primarily from a vertical controlling strategy, something supported by the TMT but closer to speaking to the academic heartland and academic staff norms was also working: voluntary networks supporting interdisciplinarity. We heard no complaints about the voluntary network strategy. In order to provide a level of understanding about how these networks were formed, supported, and operated we collected three stories from those who led the networks, one from a network sanctioned by the university, one that was developed by one of the colleges, and one that was created when academics from different disciplines found out that they had common interests. Although each story is different, common themes of the power of horizontal leadership emerge.

\section{University-level networks}

There were four networks that were sanctioned and supported by the university. Although some worked better than others, the general perception was that networks, led by a passionate leader, who links people who are interested but were not previously linked, together with committed academic staff associated with the network, are both valued and productive. This seemingly winning enabling strategy received some TMT resource support, but not enough to scale the move to interdisciplinary research.

Network activities and management fell on the shoulders of affiliated but uncompensated academic staff, the network convener, interested students, and one individual in central administration who helped set up meetings and maintain websites for each of the four University Research Networks. This is not to say staff were totally on their own, even if the conveners tended to feel that way. However, to receive their scoping budget the network must have a business plan and submit an annual report describing the use of funds and outcomes achieved. Their main evaluation happened when "people stop showing up." It was difficult to see research impact at this point in their development because unlike institutes, research that ends in publication is credited to individuals, colleges, and schools rather than the network. The way networks move from development of a common interest to grant proposals and interdisciplinary research teaming is characterized by the following example from the eyes and words of two network conveners, verified by affiliated staff, university administrators, and pieced together by the research team. It illustrates common elements and strategies. Network formation moved from a cup of coffee, a lunch, a launch, a business plan, tangible action, and a drive for self-sufficiency. Here is the story.

\section{A case in point: the cup of coffee}

The XX Network started three years ago over a cup of coffee shared by two academic staff, who knew each other slightly, after a seminar both attended. It is now in its second phase of development with at least one more to go. During the year after the "cup of coffee" these two colleagues became friendly. They were involved in a similar network, and shared supervision of a Ph.D. student even though they were in different schools. What began as a frustration with top-down systems over a "cup of coffee" grew into seeing things a little differently than their colleagues. 
The lunch. A year later, they shared their visions over lunch and things really got rolling. The more they talked about how they could create something better than the networks they were associated with, the more motivated they became to create something different. So, they sketched a plan and entered what they now called phase one. They decided to float their idea to the university funder for networks and received an immediate response that the university would invest in some "scoping" activity. In retrospect, they think that since they were known quantities with previous administrative experience, good reputations, and were enthusiastic about what they wanted to create, they were not afraid to approach top management. Whatever the reason, they received a warm welcome. They got the money they needed and, more important, visibility in top management of the university. But they had to do the heavy lifting themselves.

The launch. They sent out invitations to networks in and beyond the university and asked others who ran networks to send out the word through their sources. As one of the conveners stated, "I attended a huge number of meetings, drank huge amounts of coffee and reacquainted myself with old friends and made new friends." At this point, one of their Ph.D. students helped with the drudgework, but the conveners did not shy away from it. One hundred people showed up. At the seminar they set the scene with 6 presentations of 15 minutes each. Academic staff and members of the public (organizations, policy heads, etc.) made three presentations each. After setting the scene, they moved the people into prearranged groups with a facilitator and note taker. The facilitators were hand selected for their skills. The discussion centred on the big issues. Then they asked, "Would you be interested in a network that focused on the issues you just identified?" A report back session followed and a whole group discussion was held. As one of the conveners related, "It was good that some of the important constituents stayed until the end and described their belief that the University had some responsibility to share their knowledge in a way that the community understood."

The business plan. After the meeting, the two network conveners "hid" out for a few days and wrote the report, which led to a business plan-mission-vision-values and theme clusters (many of which did not work out; requiring new themes downstream). They presented the plan to top management and received initial funding to conduct activities outlined in the plan. No funds were used to pay staff or buy out their teaching. All participants - conveners, academic staff, and community professionals - were volunteers.

Tangible action. Phase two began by focusing on convening activities individuals were interested in around the general topic. These activities were led by academic staff and supported through some of the early funding provided by the university. A small number of activities were sponsored by external partners and were also led by academic staff. By seeking creative funding like the Rogers Scholarship (even though it is built on the Science Model), and the RAISE scholarship, which funds students who work with industry partners, the network was born and continues to flourish. As network partners talked and listened to each other, ideas began to sprout much like the initial idea of the founding network conveners. Academic staff members identified with the activities and those we interviewed seemed happy with it and are proud of their affiliation. 
The drive to self-sufficiency. The network has entered phase three. As the ideas stemming from phase two discussions made their way into proposals to funders, the role of the conveners expanded. They still do the legwork but they are also now mentors to academic staff with an idea. How to put the proposal together? Where to send it? Who needs to be approached? How to walk it through the system? The role of academic staff also is changing. They still convene workshops and seminars but now they have to do the research that is needed to impact policy or produce workable models for the practice community. The rest of the story is still being written.

As in the example above and as network theory suggests, voluntary networks are generally established in rather random ways (Festinger, Schachter, \& Back, 1950) depending on chance encounters and social proximity. Random networks generally form around issues, and whether individuals join in a network around an issue often depends on chance. The networking strategy leads to the creation of an environment that inspires and supports interdisciplinary research through a sense of purpose, collective team identity, and engagement. This is not to say that the university does not possess strong convening power. Networks are one vehicle that positively takes advantage of this university's image.

Networks also build on academic staff interests that drive volunteerism. When asked why she engaged when she was not compensated, one convener said, "It's my hobby." She whimsically said,

It really would be nice if the University would recognise the work and let it count in my workload. It also would really be nice if upfront funding could be made available to have at least one full time administrative assistant to do the coordination work. (TL3)

A second convener said, "It's the most exciting thing I have been involved in at the university." As she expressed, "people believed in the mission, values and goals of the Network and were willing to invest some time to make it work." It was obvious that notions of autonomy, complexity, purpose, and a connection between effort and reward are the qualities work must have if it is to be satisfying and motivating, as Gladwell (2008) reported.

\section{College-level networks}

The networking strategy was also used by a college whose proposal to remain in a departmental configuration was accepted by the TMT. For instance, in other colleges and schools, clusters were used to identify research areas similar to voluntary networks at the university level. In this college, similar tactics to the "cup of coffee" voluntary network example were successfully used in a more formal way.

\section{A case in point: "critical friends"}

As the Head of College explained (and verified by document review), one college held a day away for 25 people they had identified as having an interest in a major research effort. The meeting began with three proposals to implement the research effort with specific ways of addressing the problem under review and considering the resources needed to do so. Discussions followed each presentation for clarification purposes. Then the group went to a working lunch where three "critical 
friends" from outside the college gave their impressions of the project and offered suggestions.

At the lunch, participants were assigned to specific tables. The lunch started with a 15minute presentation by 1 of the critical friends. No discussion was held with the full group. The first course was served and table mates discussed the ideas presented. Then a second critical friend made their 15-minute presentation. The second course was served. Again no full group discussion occurred. The third course was served, followed by the third critical friend, and then dessert. Following dessert, the three critical friends formed a panel and responded to questions from the floor and questioned each other for 30 minutes. After a break, the full group reconvened and over the next day developed the college's plan to move the research initiatives along.

\section{Individual academic level}

Horizontal and networking principles were also found at the interdisciplinary team level. Interestingly the following example also came from the departmentalized college. Here is how an interdisciplinary team leader working horizontally used networking principles to develop a cohesive team.

\section{A case in point: the kitchen table}

I like to have the core team in proximity to each other. Oh, I know the notion is that you can do everything by internet but I like to see people regularly. So if I am collaborating with a colleague from a distance, I try to build a relationship first face to face. Then, we can use the internet - catch up at conferences and Skype. I like to have the core team around me though. My office is the centre of our operation - see the coffee in the corner - the refrigerator - the sink the fridge. When someone wants a cup of coffee during the day they come in and make it. Additionally, we all have lunch together at least 2 times a week right here around the "kitchen" table. That way I get to see everyone almost every day. Of course, I have the temperament that I don't mind being interrupted. If I am focused, I either close the door or go to a lab and work there for a while. (TL4)

\section{Summary of findings and discussion}

\section{How was the interdisciplinary change initiative organized, led, and supported at the university, college, school, and department levels?}

Although the university move to restructure based on the argument of creating more interdisciplinary research was a classic case of vertical theory management, at the same time the development of networks at university, college, and individual levels demonstrated that horizontal leadership was existing simultaneously.

\section{Did leader, manager, or professorial mindsets interfere or facilitate the interdisciplinary change initiative?}

On the one hand, the mindset of the university that the focus of this proposal was clearly the needs of research funders was perceived by staff as being "It's about money, not impacting knowledge; it's a means to securing funding" and this conflict interfered with the initiative moving forward. On the other hand, leadership that enabled the opportunity 
to "focus on issues" of mutual concern and to "build a relationship face to face" facilitated a number of potentially valuable interdisciplinary possibilities.

\section{What specific leader actions facilitated or impeded the interdisciplinary change initiative?}

The statement "Forced collaboration on interdisciplinary 'research themes' identified externally are a turn-off for most members of staff, they should emerge from below, not be imposed from above" identifies both the negative consequences of a vertical approach to change and a positive response to a horizontal approach evident from the data. In this way, the actions of the university impeded the initiative, but the work of the network leaders promoted the possibility of interdisciplinary research.

\section{Were there any unintended consequences of these efforts?}

Key issues that emerged from the data related to increased workloads (without compensation) for those who engaged in leading interdisciplinary research and the vexed issue of the need to be seen as a disciplinary expert in order to enable journal publication and promotion within a departmental structure. These created a conflict in the mind of staff who indicated that they were both supportive and positive about interdisciplinary research, but wary of the university's way of promoting it.

\section{Overall, how would the success of these efforts be rated?}

It could be argued that the move to restructure based on possible future research funding without considering how to get staff aligned with the decision first (managing change rather than just making change) might have been premature. The existence of networks at all levels suggests that there may have been alternative ways of promoting interdisciplinary research without the dislocation and disaffection felt by the restructuring activity.

The evidence presented in our findings suggests that Great Western's leaders employed some of Clark's five elements: (1) a strengthened managerial core; (2) an enhanced developmental periphery; (3) a diversified funding base, (4) a stimulated academic heartland; and (5) an entrepreneurial culture to transform universities.

By setting a clear, concise, and consistent direction through their deliberations, pronouncements, and actions, GWU strengthened their managerial core. By emphasizing institutes, centres, and networks they enhanced a developmental periphery to create a diversified funding base. In retrospect, they did many things right and some crucial things wrong.

The data suggest that the GWU used vertical leadership as a method to implement structural changes, based on its perception that this would enhance interdisciplinary research. By (2005) cites work by Bamford and Forrester (2003) and Burnes (2004) to argue that the planned approach to change ignores the presence of organizational politics and presumes that all stakeholders in a change project are willing and interested in implementing it, and that a common agreement can be reached. In the GWU case, use of these controlling strategies to restructure units and resources led to external legitimation but not internal legitimacy as many staff rejected the premise being put forward and resisted 
making the attitudinal changes necessary to make the new structures work, despite being intrinsically supportive of multidisciplinary research in itself (as reported earlier, $84 \%$ of respondents to our survey were actively involved in interdisciplinary research and $73 \%$ published in interdisciplinary journals). In this sense, our data support McKinley and Scherer (2000) who reported "restructuring leads to bifurcation or gap between the cognitions of top managers and those of their subordinates" (p. 736). The extant literature is instructive in how to create internal legitimacy. As cited earlier, staff support for strategic change initiatives is bolstered when they feel they are part of it (Welsh \& Metcalf, 2003); when shared meanings develop (Gioia \& Thomas, 1996); when top managers communicate face to face (Jarzabkowski, 2008); when the definition of quality is based on outcomes not resource inputs, and when it supports their discipline and their educative mission (Welsh \& Metcalf, 2003). The data suggest that these actions were not sufficient.

The forcing strategy left scars. Some of these scars were due to the perceived loss of identity that cherished departments provided. Others came from the unintended consequences related to increased workloads and the need to excel as a disciplinarian before even contemplating interdisciplinary research, if publications and promotions were to follow. Moreover, the insistent focus on funders' needs turned off many academic staff. As reported earlier, the respondents clearly said that trying to motivate them towards interdisciplinary research because funders will fund it is the wrong message for them, even if it was the right message for the university. Obviously the way leaders frame their messages is important and can lead to coalescence or devolution. In the case of GWU, it led to resistance.

A vertical strategy can be useful in times of strategic change to gain the attention of academic staff busy with their own work. Hence, some forcefulness and attention to big structures are often required. Command is a natural and useful tool possessed by leaders at this level, especially if the obstacles to the change are addressed. Control in some degree is necessary but it is not sufficient to achieve strategic change of the magnitude attempted by GWU. A workable option is to combine command with coordination and collaboration.

As horizontal leadership theory suggests, managing change is less about directing and controlling and more about facilitating and enabling sensemaking processes to achieve an alignment of interpretation (Bridges, 2009; Vansuch, 2009). McClellan (2011, p. 472) suggests, change is a discursive struggle to engender alternative meanings to guide organizational realities in different ways by moving from a controlling strategy of persuasion to an enabling strategy of conversation to create a shared mindset. The evidence of this study suggests that enabling strategies such as minimum specifications, shared meanings, and trust building were not fully emphasized.

Despite this, the network examples demonstrate that interdisciplinary research can develop through the shared academic interests of individuals. A conscious effort to foster the development of networks and support the common interests of individuals from different academic backgrounds may be one positive way in which universities might move this form of research forward. The evidence from the staff survey suggests resistance to the vertical approach, but no arguments were mounted against the horizontal approach. Addressing the complex issue of undertaking interdisciplinary research while simultaneously being an expert in one's discipline, for publication and promotion purposes, would be a high priority. 
The alignment literature suggests that when a common understanding of vision exists, strategic alignment can be achieved; without it, strategic alignment is more difficult (Baker \& Jones, 2008). This principle was violated in the GWU case. The common understanding necessary was stunted by insensitivity to academic norms which thwarted efforts to develop a common understanding and shared assumptions across the university (Schein, 1985) and led to many academic staff questioning the dismantling of departments in the name of fostering interdisciplinarity. The work of Kotter and Cohen (2002) is informative in this regard. They argue that significant and lasting change requires that leaders convey the change agendas in ways to ensure that everybody appreciates them not only intellectually but also emotionally. They argue that the central issue is never strategy, structure, culture, or systems, even though they are important. The core of the matter is always about changing the behaviour of people which happens mostly by speaking to people's feelings. In universities the true audience for strategic change is internal, not external if long-term gains are to be maintained.

\section{Conclusion}

While we are conscious of the limits of generalizing from a single case study, we propose that university leaders have the obligation of creating not only the case for change, but also a pathway for staff to embrace the changes proposed (Vansuch, 2009). They must recognize that they are not the only players in university change efforts (McKinley \& Scherer, 2000). They also must recognize that change involves letting go of the old before one can embrace the new and that the period of transition from one to the other will engender different emotions in different people and needs to be managed (Bridges, 2009). The data suggest that the university may have implemented change, but failed to manage change.

Our study contributes new insights in leading strategic change in universities by filling or illuminating some gaps in the lack of empirical research on change management within organizations as suggested by By (2005). By explicating how strategic change was led in this one particular site at one point of time, we extracted conceptual insights that we hope will be useful to researchers' investigations of the role of leader actions for enabling strategic change in universities. Furthermore, university leaders in other settings can also benefit from this study. The study findings also make a strong contribution for practitioners. Specifically, university leaders must manage sensemaking when pursuing strategic change. They can anticipate that the tone and values in how the change initiative is communicated and how rewards are distributed can bring the unintended consequence of separating rather than bringing staff together. At the same time, they should be aware of, and apply, horizontal leadership strategies in conjunction with vertical strategies to enable the promotion of the strategic change initiative. The extant literature provides strategies in addition to Clark's that should be considered. For instance, as reported in preceding paragraphs, staff support for strategic change initiatives is bolstered when they feel they are part of it (Welsh \& Metcalf, 2003); when shared meanings develop (Gioia \& Thomas, 1996); when top managers communicate face to face (Jarzabkowski, 2008); when the definition of quality is based on outcomes not resource inputs; and when it supports their discipline and their educative mission (Welsh \& Metcalf, 2003). 
As with any study, there are limitations. It should be noted that this study is limited by a single case and relies on the perceptions of academic staff and administrators responding to our invitation to participate. We entered the study with the purpose to shed light on the strategies and tactics used by leaders to effect strategic change in their university. We made no assumptions about the value of interdisciplinarity and what it would look like within a major university. We also recognize that there are multiple lenses to interpret findings; leadership is just one. Accordingly, caution is called for in generalizing our findings.

\section{Note}

1. The equivalent of Vice Chancellor, President or Provost in other settings.

\section{Disclosure statement}

No potential conflict of interest was reported by the authors.

\section{Funding}

This work was supported by the Adam Smith Foundation, University of Glasgow, UK.

\section{Notes on contributors}

John Pisapia is a Professor of Leadership Studies at Florida Atlantic University (US). He is also a recent Fulbright Scholar at the Chinese University of Hong Kong, a Scholar in Residence at the ChineseAmerican Center (Hong Kong), the Adam Smith Research Professor at the University of Glasgow, and the founder of the Strategic Leader Network (SLN), a global learning community focused on the principles of strategic and entrepreneurial leadership.

Jamila Razzaq is associated with the University of Glasgow School of Education and is involved in a number of research and teaching initiatives there including interdisciplinary research, teacher professionalism, the impact of family and neighbourhood on career aspirations of young people, and the impact of regeneration and games on health and well-being of people in the deprived areas of Glasgow. Previously, she taught in Pakistan for 17 years. She has a wide range of qualifications, skills, and experience and has developed expertise in Educational Leadership, Change Management, Pakistani Education (secondary and higher), and Gender Issues.

Tony Townsend is Professor of Educational Leadership at Griffith Institute for Educational Research in Griffith University and at the School of Education at the University of Tasmania. He was Chair of Public Service, Educational Leadership, and Management at the University of Glasgow when the current research was undertaken. Prior to this appointment he worked in universities in Australia and the United States. He has authored or edited 11 books and numerous chapters and articles in the fields of leadership, school effectiveness, and educational reform. He has worked with educators in more than 50 countries.

\section{References}

Baer, M., Dirks, K., \& Nickerson, J. (2013). Microfoundations of strategic problem formulation. Strategic Management Journal, 34(2), 197-214.

Baker, J., \& Jones, D. (2008). A theoretical framework for sustained strategic alignment and an agenda for research. Proceedings of JAIS Theory Development Workshop (Sprouts: Working Papers on Information Systems, 8(16)). 
Balogun, J., \& Johnson, G. (2005). From intended strategies to unintended outcomes: The impact of change recipient sensemaking. Organization Studies, 26(11), 1573-1601.

Bamford, D., \& Forrester, P. (2003). Managing planned and emergent change within an operations management environment. International Journal of Operations \& Production Management, 23(5), 546-564.

Bandura, A. (1986). Social foundations of thought and action: A social cognitive theory. Englewood Cliffs, NJ: Prentice Hall.

Barabási, A. (2002). Linked: The new science of networks. New York, NY: Basic Books.

Bass, B. (1990). Bass and Stogdill's handbook of leadership: Theory, research and managerial applications (3rd ed.). New York, NY: Free Press.

Birkinshaw, J., Crilly, D., Bouquet, C., \& Lee, S. (2016). How do firms manage strategic dualities? A process perspective. Academy of Management Discoveries, 2(1), 51-78.

Birnbaum, R. (1991). How colleges work: The cybernetics of academic organization and leadership. San Francisco, CA: Jossey-Bass.

Birnbaum, R. (2000). Management fads in higher education: Where they come from, what they do, why they fail. San Francisco, CA: Jossey-Bass.

Blake, R., \& Mouton, J. (1964). The managerial grid: The key to leadership excellence. Houston, TX: Gulf.

Boal, K., \& Hooijberg, R. (2000). Strategic leadership research: Moving on. The Leadership Quarterly 11, 515-549.

Bowman, E., \& Singh, H. (1993). Corporate restructuring: Reconfiguring the firm. Strategic Management Journal, 14, 5-14.

Bridges, W (2009). Managing transitions: Making the most of change. Boston, MA: De Capo Press.

Burnes, B. (2004). Managing change: A strategic approach to organisational dynamics (4th ed.). Harlow: Prentice Hall.

Burns, J. (1978). Leadership. New York, NY: Harper \& Row.

By, R. T. (2005). Organisational change management: A critical review. Journal of Change Management, 5(4), 368-380.

Clark, B. (1998a). Creating entrepreneurial universities: Organizational pathways of transformation. New York, NY: Pergamon Press.

Clark, B. (1998b). The entrepreneurial university: Demand and response. Tertiary Education and Management, 4(1), 5-16.

Coffey, A., Holbrook, B., \& Atkinson, P. (1996). Qualitative data analysis: Technologies and representations. Sociological Research Online, 1(1) [downloaded July 17, 2016].

Cohen, L., Manion, L., \& Morrison, K. (2007). Research methods in education (6th ed.). London: Routledge.

Corden, A., \& Sainsbury, R. (2006). Using verbatim quotations in reporting qualitative social research: Researchers' views. York: Social Policy Research Unit, University of York.

Cox, J., Pearce, C., \& Perry, M. (2003). Toward a model of shared leadership and distributed influence in the innovation process: How shared leadership can enhance new product development team dynamics and effectiveness. In C. Pearce \& J. Conger (Eds.), Shared leadership: Reframing the hows and whys (pp. 48-76). Thousand Oaks, CA: Sage.

Cyert, R., \& March, J. (1963). A behavioral theory of the firm. Englewood Cliffs, NJ: Prentice Hall.

Day, D. (2000). Leadership development: A review in context. The Leadership Quarterly, 11(4), 581613.

Drath, W. (2001). The deep blue sea: Rethinking the source of leadership. San Francisco, CA: Jossey-Bass.

Duderstadt, J., \& Womack, F. (2003). The future of the public university in America: Beyond the crossroads. Baltimore, MD: Johns Hopkins University Press.

Festinger, L., Schachter, S., \& Back, K. (1950). Social pressures in informal groups: A study of human factors in housing. Stanford, CA: Stanford University Press.

Fiedler, F. (1967). A theory of leadership effectiveness. New York, NY: McGraw-Hill.

French, S. (2009). Re-thinking the foundations of the strategic business process. Journal of Management Development, 28(1), 51-76.

Fu, P., \& Yukl, G. (2000). Perceived effectiveness of influence tactics in the United States and China. The Leadership Quarterly, 11(2), 252-266. 
Gioia, D., \& Thomas, J. (1996). Identity, image, and issue interpretation: Sensemaking during strategic change in academia. Administrative Science Quarterly, 41, 370-403.

Gladwell, M. (2008). Outliers: The story of success. New York, NY: Little, Brown.

Goldstein, J., Hazy, J., \& Lichtenstein, B. (2010). Complexity and the nexus of leadership: Leveraging nonlinear science to create ecologies of innovation. Englewood Cliffs, NJ: Palgrave Macmillan.

Gouldner, A. (1954). Patterns of industrial bureaucracy. Glencoe: Free Press.

Gronn, P. (2002). Distributed leadership as a unit of analysis. The Leadership Quarterly, 13, 423-451.

Harris, L., \& Ogbonna, E. (2002). Exploring service sabotage: The antecedents, types and consequences of frontline, deviant, antiservice behaviors. Journal of Service Research, 4(3), 163-183.

House, R. (1971). A path-goal theory of leader effectiveness. Administrative Science Quarterly, 16, 321338.

House, R., \& Aditya, R. (1997). The social scientific study of leadership: Quo vadis? Journal of Management, 23(3), 409-473.

Hughes, M. (2011). Do 70 per cent of all organizational change initiatives really fail? Journal of Change Management, 11(4), 451-464.

Jarzabkowski, P. (2008). Shaping strategy as structuration process. The Academy of Management Journal, 51, 621-650.

Keller, S., \& Price, C. (2011). Beyond performance: How great organizations build ultimate competitive advantage. Hoboken, NJ: John Wiley.

Kezar, A. (2001). Understanding and facilitating organizational change in the 21st century: Recent research and conceptualizations (ASHE-ERIC Higher Education Reports, 28(4)). Washington, DC.

Kotter, J. (1995). Leading change: Why transformation efforts fail. Harvard Business Review, 73(2), 5967.

Kotter, J., \& Cohen, D. (2002). The heart of change: Real-life stories of how people change their organizations. Boston, MA: Harvard Business School Press.

Layder, D. (2006). Understanding social theory (2nd ed.). London: Sage.

Li, Y., Guohui, S., \& Eppler, M. (2008). Making strategy work: A literature review on the factors influencing strategy implementation (Working Paper 2/2008, pp. 1-46). Lugano: Institute for Corporate Communication.

Lichtenstein, B., Uhl-Bien, M., Marion, R., Seers, A., Orton, J., \& Schreiber, C. (2006). Complexity leadership theory: An interactive perspective on leading in complex adaptive systems. Emergence: Complexity \& Organization, 8, 2-12.

Machiavelli, N. (1992). The prince (N. H. Thomson, Trans.). New York, NY: Dover. (Original work published 1513.)

McClellan, J. (2011). Reconsidering communication and the discursive politics of organizational change. Journal of Change Management, 11(4), 465-480.

McGrath, C., \& Krackhardt, D. (2003). Network conditions for organizational change. Journal of Applied Behavioral Science, 39(3), 324-336.

McKinley, W., \& Scherer, A. (2000). Some unanticipated consequences of organizational restructuring. Academy of Management Review, 25(4), 735-752.

McNamee, S., \& Gergen, K. (1999). Relational responsibility: Resources for sustainable dialogue. Thousand Oaks, CA: Sage.

Merton, R. (1936). The unanticipated consequences of purposive social action. American Sociological Review, 1(6), 894-904.

Meyer, A., Gaba, V., \& Colwell, K. (2005). Organizing far from equilibrium: Nonlinear change in organizational fields. Organization Science, 16(5), 456-473.

Meyer, J., \& Rowan, B. (1977). Institutionalized organizations: Formal structure as myth and ceremony. American Journal of Sociology, 83(2), 340-363.

Morrison, M. (2007). What do we mean by educational research. In R. J. Briggs \& M. Coleman (Eds.), Research methods in educational leadership and management (2nd ed., pp. 13-36). Los Angeles, CA: Sage.

Mullins, L. (2006). Essentials of organisational behaviour (8th ed.). Harlow: Pearson Education.

National Academy of Sciences. (2004). Facilitating interdisciplinary research. Washington, DC: Author. 
Pearce, C. (2004). The future of leadership: Combining vertical and shared leadership to transform knowledge work. Academy of Management Executive, 18(1), 47-57.

Pearce, C., \& Conger, J. (2003). All those years ago: The historical underpinnings of shared leadership. In C. Pearce \& J. Conger (Eds.), Shared leadership: Reframing the hows and whys of leadership (pp. 1 -18). Thousand Oaks, CA: Sage.

Pettigrew, A. (1985). The awakening giant: Continuity and change in Imperial Chemical Industries. Oxford: Blackwell.

Pfeffer, J. (1981). Power in organizations. Marshfield, MA: Pittman.

Pisapia, J. (2009). The strategic leader: New tactics for a globalizing world. Charlotte, NC: Information Age.

Podsakoff, P., MacKenzie, S., Podsakoff, N., \& Lee, J. (2003). The mismeasure of man(agement) and its implications for leadership research. The Leadership Quarterly, 14, 615-656.

Rajagophalan, N., \& Sprieitzer, G. (1996). Toward a theory of strategic change: A multi-lens perspective and integrative framework. Academy of Management Review, 22(1), 48-79.

Razzaq, J., Townsend, T., \& Pisapia, J. (2013). Towards an understanding of interdisciplinarity: The case of a British university. Issues in Interdiscipinary Studies, 31, 149-173. Retrieved from http://www. oakland.edu/ais/publications

Remenyi, D., Williams, B., Money A., \& Swartz E. (1998). Doing research in business and management. London: Sage.

Rhoten, D. (2003). A multi-method analysis of social and technical conditions for interdisciplinary collaboration (Final Report to the National Science Foundation (BCS-0129573)). San Francisco, CA: The Hybrid Vigor Institute.

Schein, E. (1985). Organizational culture and leadership (1st ed.). Hoboken, NJ: John Wiley.

Tenkasi, R., \& Chesmore, M. (2003). Social networks and planned organizational change: The impact of strong network ties on effective change implementation and use. The Journal of Applied Behavioural Science, 39(3), 281-300.

Tierney, W. (1988). Organizational culture in higher education: Defining the essentials. The Journal of Higher Education, 59, 2-21.

Triandis, H. (1995) Individualism and collectivism. Boulder, CO: Westview.

Uhl-Bien, M. (2006). Relational leadership theory: Exploring the social processes of leadership and organizing. The Leadership Quarterly, 17(6), 654-676.

Uhl-Bien, M., Marion, R., \& McKelvey, B. (2007). Complexity leadership theory: Shifting leadership from the industrial age to the knowledge era. The Leadership Quarterly, 18, 298-318.

Van de Ven, A. (1992). Suggestions for studying strategy process: A research note. Strategic Management Journal, 13, 169-188.

Vansuch, G. (2009, September 8). Change management: moving from good intentions to good results. Longmont, Co: Presentation to the American Society for Quality.

Welsh, J., \& Metcalf, J. (2003). Faculty and administrative support for institutional effectiveness activities: A bridge across the chasm? The Journal of Higher Education, 74(4), 445-468.

Yin, R. (2009). Case study research: Design and methods (4th ed.). Thousand Oaks, CA: Sage. 


\title{
Strategic change in the academy: controlling and/ or enabling strategies
}

\author{
John Pisapia, Tony Townsend \& Jamila Razzaq
}

To cite this article: John Pisapia, Tony Townsend \& Jamila Razzaq (2016): Strategic change in the academy: controlling and/or enabling strategies, Journal of Change Management, DOI: 10.1080/14697017.2016.1253601

To link to this article: http://dx.doi.org/10.1080/14697017.2016.1253601

\section{曲 Published online: 15 Nov 2016.}

Submit your article to this journal $[\pi$

Q View related articles $\longleftarrow$

View Crossmark data $\nearrow$ 